abdominal wall might be a calculus lodged in a bladder diverticulum near the fundus. But the sound struck no hard substance. Lateral lithotomy was out of the question and accordingly $I$ opened above the pubes and removed a calculus which Mr. W. H. Clayton-Greene, the surgical registrar, has thus described: "The mass was about the size of a large walnut and consisted of some 10 to 12 layers of laminated tough material in appearance like wash-leather and like the decolourised blood clot from an aneurysmal sac. The layers could be separated without difficulty. In the centre of the mass was found a soft friable nucleus of mixed wates and phosphates about as large as a kidney-bean. This was doubtless the origin of the trouble and round it blood had been deposited in laminæ which had gradually been decolourised." No bladder pouch was discovered and it is not easy to account for the deposition of laminated blood clot round a nucleus subjected, as it must have been, to the perpetual wash of urine. I have never seen anything like it before. After the operation the child was kept in a warm bath and recovery was uninterrupted. He very soon lost his pain and began to take as much interest in his surroundings as his idiot state would allow. He was discharged well on Feb. 10th.

\section{THE MICROSCOPICAL OBSERVÁTION OF THE GLYCOGEN REACTION.}

\section{By Dr. G. SPEZIA.}

THE microscopical reaction with iodine showing the presence of glycogen in the white corpuscles may occur under both physiological and pathological conditions.

Physiologically, I have observed it in the human subject during the digestive leucocytosis following hearty meals. Studying this phenomenon in guinea-pigs which did not show this reaction in their blood I succeeded in producing it very distinctly, not only with injections of peptone into the peritoneal cavity, as Gabrietschewsky did, but I obtained it even with subcutaneous injections of fats (olive oil), albuminoids (peptone), and carbohydrates (glucose). Physiologically, I have observed it also in pregnant guinea-pigs. I therefore place on record this reaction with the formation of glycogen by the action of various diastases from various nutritive materials which exert a positive chemiotaxic action.

Pathologically, I have observed that it is always accompanied by hyperleucocytosis in excess of that which has long been known to occur in suppuration and that it is manifested in the polynuclear neutrophile cells ; it is found in inflammatory foci and also in the blood. In the blood it is the more evident in proportion to the closeness of the relations between the blood and the organs affected (as in croupous pneumonia, for instance).

The glycogenic reaction of the anæmias is found also in the hæmopoietic organs. This reaction is very evident in the sputa in inflammatory diseases of the lungs; in these cases I have observed it, not only in the white corpuscles, but also (and I believe that I was the first to do so) in the large phagocytes in which karyokinetic figures were displayed.

This reaction is the expression of a resistance of the organism to toxic agents, whatever be their origin, whether bacterial or not, a resistance which places in a circle (il quale mette in (ircolo) a substance (glycogen) which must serve to arouse an increased degree of defensive activity, as is proved by the following facts. 1. This reaction is manifested after the injection of various nutritive substances. 2. In pathological cases it attains its highest point in the inflammatory centre, as, for instance, in the foci of pneumonia or bronchopneumonia, in which I have observed droplets of glycogen of a size from $0.5 \mu$ to $20 \mu$ (from 0.00002 to 0.0008 of an inch). 3. It is greater in severe toxic affections than in mild ones. 4. It is accompanied by hyperleucocytosis. 5. It is accompanied by evidences of cellular division (for example, in tumours).

Turin.

\section{NOTE ON A CASE OF HYDATID CIST OF THE} SPLEEN.

By Frank R. Seager, L.R.C.P., L.R.O.S. Edin., L.F.P.S. GLASG. HOUSE SURGEON, SALOP INFIRMARY, SHREWSISTRY.

A Boy, aged 11 years, was admitted into the Salop Infirmary on Jan. 11th, 1903, under the care of Mr. A.
Jackson, the senior surgeon, complaining of "a lump in the stomach on the left side." The history of the case was that four months previously he had first noticed a swelling below the ribs on the left side. The size of this swelling was not at first definitely noticed and there was no pain, but it gradually increased and the lad began to experience slight pain which he likened to "stitch." It was now noticed that the swelling varied in size, being larger after a meal and at night. There was no sickness and the pain was not aggravated by taking food. The bowels acted regularly. The family history was very good. As regards the habits of the boy it was elicited that he was fond of accompanying keepers in beating for game and that he used to drink freely of the water in brooks and to eat watercress which was plentiful in his neighbourhood. Physically he was robust and well nourished. In the abdomen a swelling of the size of a small orange was distinctly noticeable in the left hypochondrium, projecting from below the costal margin, with its centre just internal to the nipple line. Palpation of the tumour, beyond giving the sense of a cystic swelling, revealed nothing to suggest its nature or as to which was the organ affected. The percussion note was resonant over the tumour. There were no increase in splenic or renal dulness, no pain or tenderness on manipulation, and no appreciable movement with inspiration. The urine showed a trace of albumin. The diagnosis was thought to lie between a hydro-nephrosis or a hydatid cyst of some part.

Two days after admission an incision was made under an anresthetic over the tumour and on opening the peritoneal cavity the spleen at once presented in the wound, with twothirds of its anterior surface occupied by a tense, shining, yellow-coloured tumour which fluctuated on palpation. This was tapped and fully half a pint of clear limpid fluid was drawn off. The wound made by the tapping was then enlarged and a thick cyst.wall was shelled out in the ordinary way. The wall of the cavity was then stitched to the skin, a tube was inserted, and the rest of the wound was stitched. The boy made an uninterrupted recovery. The cyst was single with no daughter cysts.

For permission to publish this note, which $\mathrm{I}$ hope may prove of interest from the diagnostic point of view, I am indebted to Mr. Jackson.

\section{Mttedital Suxieties.}

\section{PATHOLOGICAL SOCIETY OF LONDON.}

The Excretion of Alkalies in certain Conditions of Renal Disease._Ehrlich's Dimethyl (p) Amido-benzaldehyde Reaction.-The Relation existing between Uric Acid Excretion and the Breaking Don'n of White Blood Corpuscles.

A MEETING of this society was held on March 3rd, Dr. W. D. Halliburton, the Vice-President, being in the chair.

Dr. W. P. Herringham read a paper on the Excretion of Sodium and Potassium in cases of Renal Disease. In experiments cn the toxicity of urine when injected into the blood of animals, an account of which was given to the society three years ago, he had been led to disbelieve Bouchard's explanation and to conclude, with Feltz and Ritter, Astachensky, and others, that all the symptoms seen in rabbits might be accounted for by the potassium salts held in solution. There was no necessary connexion between the toxicity of urine and uræmia. Indeed, it seemed to him probable that uræmia was not due tu the retention of any normal product $b^{\prime}$ to something abnormal. Nevertheless, he had thoughr it advisable to examine the excretion of scdium and potassium in renal disease to see if it varied from the standard of health. The standard of health was not, however, very certain, it varied within considerable limits. He had expected that if any marked change occurred in cases of nephritis it would be in the excretion of potassium. He found, on the contrary, that the great varia. tion was on the side of sodium. In patients who died there was found a great, in some cases a complete, retention of sodium. He had made 16 analyses in 11 cases of chronic interstitial nephritis and of these six were fatal. In every one of them the sodium excretion was $n i l$ or very small. lt was not so in any of the five cases which did not end fatally. 